\title{
Francesco Altomare - the remarkable mathematician and human being
}

\author{
Mirella Cappelletti Montano, Vita LeOnessA*, ANd LaRs-Erik Persson
}

\begin{abstract}
We laconically describe the great contributions of Professor Francesco Altomare to mathematical research and Ph.D education, and his unique status in the mathematical community. In particular, we present and give examples of his innovative and great achievements related to the following areas of mathematics: Functional Analysis, Operator Theory, Potential Theory, Approximation Theory, Probability Theory, Function Spaces, Choquet's Theory, Dirichlet's Problem and Semigroup Theory. Moreover, we report on and give concrete examples of his unique way to work together with Ph.D students, both before and sometimes also after their dissertation. Finally, we shortly describe his remarkable "class travel" from "simple" conditions with no academic traditions in his family in the small town Giovinazzo to finally become the broad, ingenious, and powerful mathematician he is regarded to be today.
\end{abstract}

Keywords: Francesco Altomare, History of Mathematics, Functional Analysis, Operator Theory, Potential Theory, Approximation Theory, Probability Theory, Function Spaces, Choquet's Theory, Dirichlet's Problem, Semigroup Theory and Evolution Equations, Ph.D education.

2020 Mathematics Subject Classification: 01A99, 31C99, 41A25, 41A63, 46E05, 47D06, 47D07.

\section{INTRODUCTION}

It is with great enthusiasm that we have accepted the proposal of our friend Professor Tuncer Acar to contribute to the Special Issue in honor of Professor Francesco Altomare's 70th birthday and we have decided to write a paper on his academic life.

First of all, we want to pronounce that in this limited amount of pages it is absolutely impossible to give a fair description of Francesco concerning his work, impact in the mathematical community, and his really unique and strong character. However, we will do our best to give the readers at least some interesting information about this remarkable man and his work. We have the following relations to Francesco: the two first authors are his former students, which still collaborate scientifically with him, while the third author is a typical representative of the mathematical community with broad knowledge about Francesco and his impressive status in the mathematical world.

The paper is organized as follows. In Section 2, we briefly describe the first steps and related personal information about Francesco. In particular, we shortly report on his really remarkable "class travel" from "simple" conditions, in a family with no academic traditions in the small town Giovinazzo, to finally become the broad, innovative and powerful mathematician he is regarded to be today.

In Section 3, we continue by delivering selected information from Francesco's early career from 1975 till around 1990. His strong thesis Choquet's Theorems and Integral Representation Theory for Convex Compact Subsets was a perfect basis, which influenced several subsequent research works, sometimes in collaboration with other researchers. Correspondingly, we mention

Received: 21.12.2020; Accepted: 14.01.2021; Published Online: 01.03.2021

*Corresponding author: Vita Leonessa; vita.leonessa@unibas.it

DOI: $10.33205 / \mathrm{cma} .844390$ 
some of these collaborations that we know Francesco considers especially important during that period.

Section 4 is used to inform about another activity for which Francesco is especially well known, namely he was the main organizer of six international FAAT (Functional Analysis and Approximation Theory) conferences which gathered together more than 900 participants totally. In this section, we also mention some later collaborations that we know have been especially significative for Francesco and his scientific work.

In Section 5, we give some examples of, in our opinion, the most important information from Francesco's very impressive Curriculum Vitae. Besides his obviously strong merits in mathematical research, he is well known for his unique way to supervise Ph.D students (see also Section 7) and as organizer and main speaker at international conferences. Moreover, he is Editor-in-Chief for a very high level international journal as well as Editor of several other journals including the current one. This is well known all over the world but what is less known is that Francesco has great merits and talents also outside the university sphere, e.g., concerning his involvement in inspiring students in basic schools in projects whose aim is to connect mathematics to others fields such as art, music, and literature.

Section 6 is the most important part of this paper. There we make a serious attempt to shortly describe some important parts of Francesco's impressive and innovative scientific contributions related to the following areas of Mathematics: Functional Analysis, Operator Theory, Potential Theory, Approximation Theory, Probability Theory, Function Spaces, Choquet's Theory, Dirichlet's Problem and Semigroup Theory.

Section 7 is reserved for a discussion of the unique and supportive way Francesco uses when supervising and guiding Ph.D students, PostDocs etc.; he sometimes even continues to collaborate with them a long time after they have finished their Ph.D program. We think that this can be a good model and leading star for many of us in the supervision of our own students.

Finally, in Section 8, we do a short summary focused on final words about the remarkable mathematician and human being Francesco, including some especially warm Mirella's, Vita's and Pers(s)onal words related to his anniversary.

\section{THE FIRST STEPS AND PERSONAL INFORMATION}

Francesco Altomare was born on May 18, 1951 in Giovinazzo, a nice town in Puglia (Italy) with a magnificent medieval center, located on the Adriatic Sea, and 18 kilometers away from Bari, the regional capital. Francesco has always lived in this town, to which he is deeply attached.

His father, Luigi Altomare (1898-1963), was an esteemed barber, and his mother, Maria Giordano (1915-1989), was a pious housewife. Francesco also had three siblings: one sister, Gesuela (1949-1999), and two brothers Salvatore (1953-1989) and Giovanni (1955).

In 1963, his father Luigi died prematurely and so his family suddenly found themselves facing a very difficult and uncertain future.

Despite this, his mother and Gesuela, on the advice of several professors who saw Francesco's potential, taking on themselves great sacrifices and supported by a strong desire for a social redemption, allowed him to continue his high school studies during which he had the opportunity to study and to become keen not only on Mathematics but also on the great Greek and Latin Classics, on art, especially on the Renaissance and the Impressionism, as well as on poetry and Italian literature. Francesco has continued to cultivate the interests in these subjects throughout his life.

In 1970, Francesco enrolled in a degree course in Mathematics at the University of Bari, where he graduated in 1975. 
During his high school and university studies, Francesco contributed to the family purse by doing small jobs, including giving amateur guitar lessons, a musical instrument he loves very much, and which he himself learned to play during the youth protests in 1968.

Between 1968 and 1972, Francesco played in a beat band where he alternated between playing the guitar and the electronic keyboard. Though the band mainly performed beat music, Francesco was also passionate about soul and Neapolitan music.

Raised and educated with a strong sense of religion, Francesco established a deep friendship with

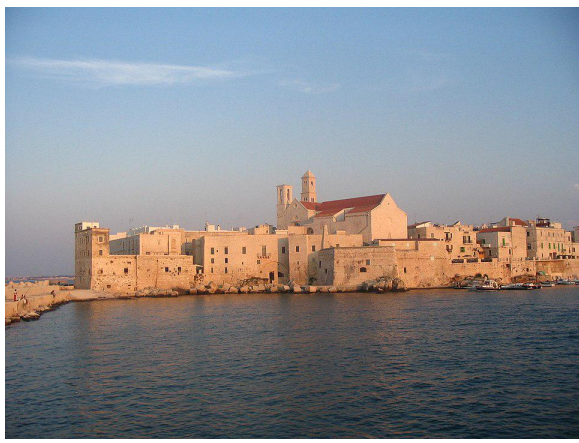

The old town of Giovinazzo. some enlightened priests who have been very close to him since his youth. He often participated in religious functions, performing musical pieces on the church organ.

Several sports activities count among his youthful passions, in particular basketball, which he played in provincial championships. He also coordinated a sports association that gathered young people from Giovinazzo, carrying out a noteworthy social action.

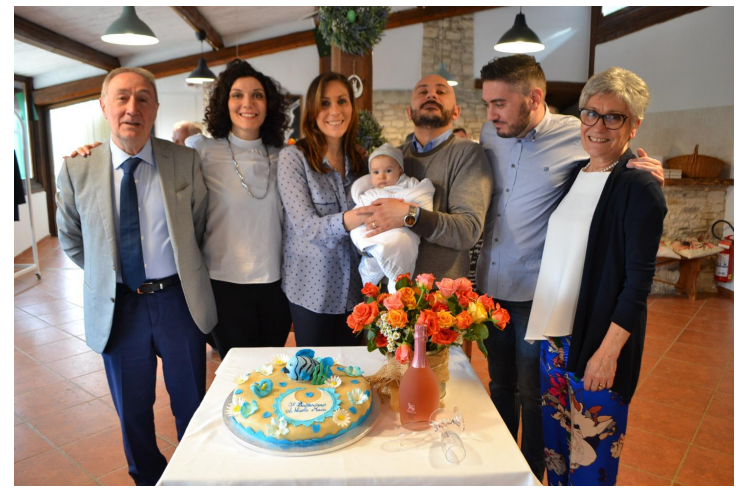

April 2019 -The Altomare family on the occasion of the baptism of Nicola Maria. From the left: Francesco, his daughterin-law Nunzia, Bianca Maria and her husband Vittorio with their son Nicola Maria, Gianluigi and Raffaella.

In 1975, Francesco was invited to partake in the local city politics. He was elected as a member of the city council for a five-year term, the first three of which he was a city councilor as well. To these days, he is still very involved in promoting some cultural activities in Giovinazzo. In particular, he has co-founded a cultural association which, among other things, makes a library for children available to citizens. Moreover, periodically he gives some lectures on Mathematics which are intended to a broad audience and which have the aim to show the importance and usefulness of this Science, together with its harmony and beauty.

In 1968, Francesco met Raffaella Bavaro whom he married in 1979. Raffaella accompanied Francesco with love and spirit of selfsacrifice by supporting him throughout the whole scientific and academic activities. They have two children: Bianca Maria (1983) and Gianluigi (1986). Bianca Maria, in turn, gave birth to a son, Nicola Maria (2019).

\section{THE EARLY CAREER (1975-AROUND 1990)}

During his degree in Mathematics program, Francesco attended some courses given by Professors Giuseppe Muni and Giovanni Aquaro (1920-2014) who greatly influenced his future studies in Real and Functional Analysis (Locally Convex Spaces, Integration Theory, Measure Theory, General Topology). They acted as mentors for Francesco throughout his career and they all forged a strong tie of affection and friendship. 


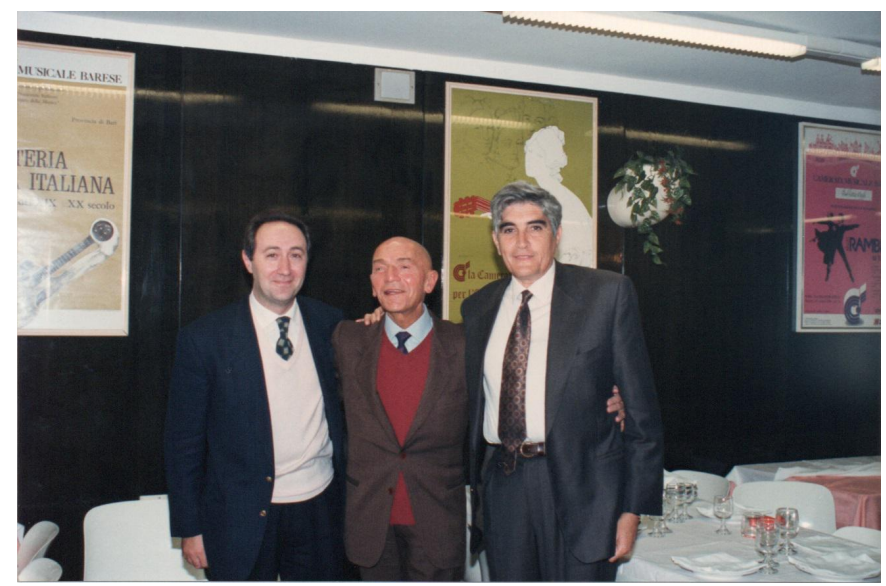

Bari, November 1990 - A party on the occasion of the retirement of Professor Giovanni Aquaro.

From the left: Francesco, Giovanni Aquaro, Giuseppe Muni.

Under the supervision of Professor Giuseppe Muni, Francesco wrote his thesis Choquet's Theorems and Integral Representation Theory for Convex Compact Subsets. This topic influenced several subsequent research works of his. The thesis contained new results, which were published in 1977 (see [1]). That was the first paper Francesco wrote.

Before completing his degree program in Mathematics, he was awarded a junior C.N.R. (Consiglio Nazionale delle Ricerche) grant. From 1975 to 1978, he was a senior research fellow at the Institute of Mathematical Analysis of the University of Bari. From 1978 until 1985, and from 1985 until 1987, he was an assistant professor and, respectively, an associate professor, at the Faculty of Sciences of the University of Bari. He was appointed full professor at the Faculty of Sciences of the University of Basilicata in Potenza in 1987. In 1990, he moved to the University of Bari, where he is currently employed, on the same chair Professor Aquaro left having reached the retirement age.

During the summer of 1975, Francesco attended a course on locally convex spaces given by Professor John Horvath (1924-2015) of the University of Maryland, at a Summer School in Perugia. During the course, Professor Horvath suggested Francesco to discuss the main results of his thesis with Professor Heinz Bauer (1928-2002) from the University of Erlangen-Nürnberg. This was the starting point of his long and fruitful cooperation with Professor Bauer, which inspired Francesco's subsequent studies and researches on abstract Choquet boundaries and relevant Dirichlet problems, Korovkin-type Approximation Theory in continuous function spaces, and Probability Theory.

In 1978, Professor Bauer invited Francesco to attend a conference on Function Spaces in Oberwolfach. That was Francesco's first conference abroad and, among other things, his first meeting with Professor Ivan Netuka (1944-2020) from the Charles University of Praha. The scientific cooperation developed by Professor Netuka and Francesco has been productive and essentially focused on the applications of Choquet Integral Representation Theory to Potential Theory. In 1997, on the invitation of Netuka, Francesco taught a short course on Korovkin-type Approximation Theory in Banach spaces at a Spring School in Paseky, Czech Republic.

Through Professor Bauer, Francesco had the opportunity to meet Professor George Maltese (1931-2009) from the University of Münster. The cooperation between them and some Maltese's Ph.D students - Michael Pannenberg and Ferdinand Beckhoff-focused on the development 
of Korovin-type Approximation Theory in the framework of Banach algebras. It has also been enriched by several exchanges of visits, one of which, in 1985, was supported by a joint research NATO fellowship.

Thanks to Professor Maltese, in 1980, Francesco came into contact with Professor Gustave Choquet (1915-2009), from the University of Paris VI, and his research group - Richard Becker, Hicham Fakhoury, Gilles Godefroy, Marc Rogalski, Jean Saint-Raymond. He spent two long research periods in Paris in 1980 and 1981, by also participating in the activities of the Séminaire Initiation à l'Analyse.

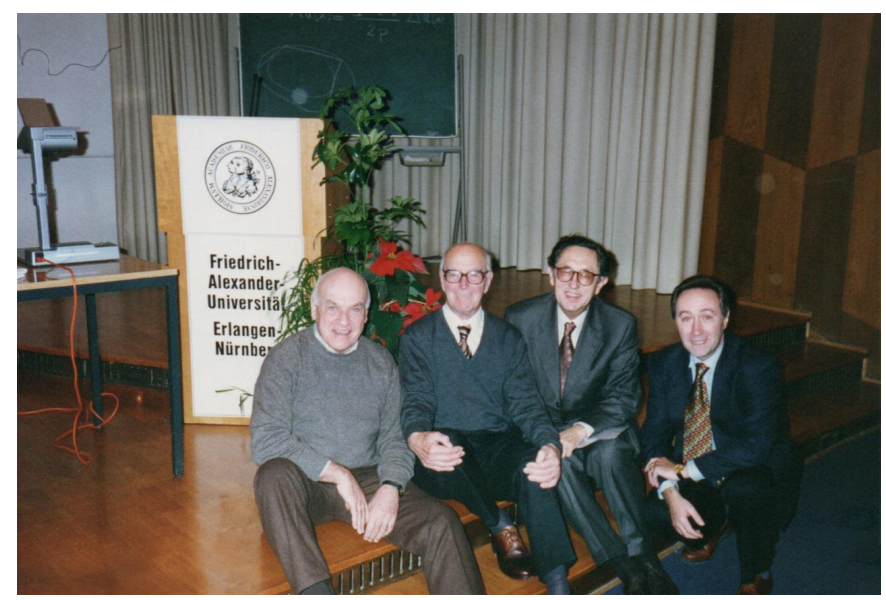

Erlangen, December 1995 - A conference on the occasion of the retirement of Professor Heinz Bauer. From the left: George Maltese, Gustave Choquet, Heinz Bauer, Francesco.

During the above-mentioned seminar activities, Francesco took up with Professor Rainer Nagel from the University of Tübingen. With him Francesco established a fruitful and long cooperation as they were both interested in Positive Operators, Semigroup Theory and Evolution Equations, Markov Semigroups and Stochastic Processes. Several exchanges of visits were realized. Moreover, on the light of the emerging collaboration with Francesco, in 1993, Professor Nagel was appointed the post of full professor at the University of Bari until 1995, when he came back to the University of Tübingen.

In 1987, Francesco was appointed full professor at the University of Basilicata in Potenza where he taught until 1990. This period was one of the most fruitful of his scientific and academic career. The University of Basilicata was a new university, inaugurated in the 1983-84 academic year. It was established after the terrible earthquake of 1980, which devastated the Campania and Basilicata regions. That same year, Francesco was called to manage the newborn Institute of Mathematics and organize it (library, numerical and computer laboratories, administrative offices, teaching and researches activities, and so on).

\section{THE FAAT CONFERENCES AND LATER COLLABORATIONS}

During Francesco's stay in Potenza, many young professors from several Italian and foreign universities took up service at the University of Basilicata. Soon after, an agreeable atmosphere of friendship and strong cohesion was established among them. It was in this atmosphere that Francesco met Professor Giuseppe Mastroianni, coming from the University of Naples Federico II. A brotherly friendship built on mutual esteem and collaboration was immediately born 
between them. Their common scientific interests included Approximation Theory, especially approximation problems by means of positive operators.

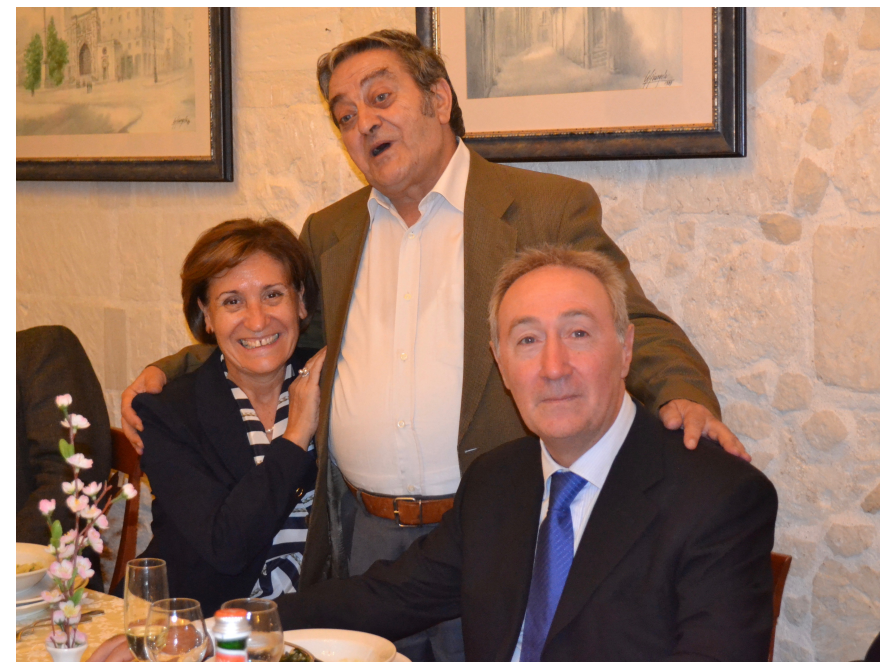

Lecce, September 2011: A party on the occasion of Francesco's 60th birthday. From the left: Raffaella, Giuseppe Mastroianni, and Francesco.

They also developed the idea to organize a conference on Functional Analysis and Approximation Theory which took place at Acquafredda di Maratea (Potenza) in 1989. The conference was highly appreciated and this encouraged the organization of five further editions (1992, 1996, 2000, 2004, and 2009). Francesco managed the Proceedings volumes of all editions which were published in esteemed mathematical journals.

All six editions received a general appreciation for the organization, level of the topics covered, and the beauty of the locations where they took place. This appreciation is documented, e.g., in the monograph [29, Section 8.2.7.15, p. 626]. For a complete overview of the scientific programs of the Maratea Conferences, we refer the reader to [12].

During the time spent in Potenza, a deep and affectionate friendship with Professor Michele Campiti was also consolidated. Professor Campiti graduated in 1985 from the University of Bari and came to the University of Basilicata as a guest lecturer and on an I.N.d.A.M. research fellowship under Francesco's supervision. He is now a full professor at the University of Salento in Lecce, and generously contributed to the organization of all the FAAT conferences. He and Francesco wrote the monograph [14], which has been highly appreciated by the international community since its year of publication in 1994. For many years, it was also listed among the top ten most cited monographs in the Approximation Theory section of Mathematical Reviews.

Other scientific collaborators which characterized the period in Potenza are Biancamaria Della Vecchia, Sapienza University of Rome, who, among other things, enthusiastically participated in the organization of several editions of the Maratea Conferences, as well as Professors Manuel Valdivia (1928-2014), University of Valencia, Vincenzo Moscatelli (1945-2008), University of Lecce, Pierluigi Papini, University of Bologna, and Carlo Franchetti, University of Firenze. Those scientific collaborations were mainly concerned with Fréchet spaces, Banach spaces and abstract Approximation Theory.

At the end of 1989, Francesco established the first contacts with Professor Ioan Raşa from the Technical University of Cluj-Napoca. This was the start of a long and productive collaboration 


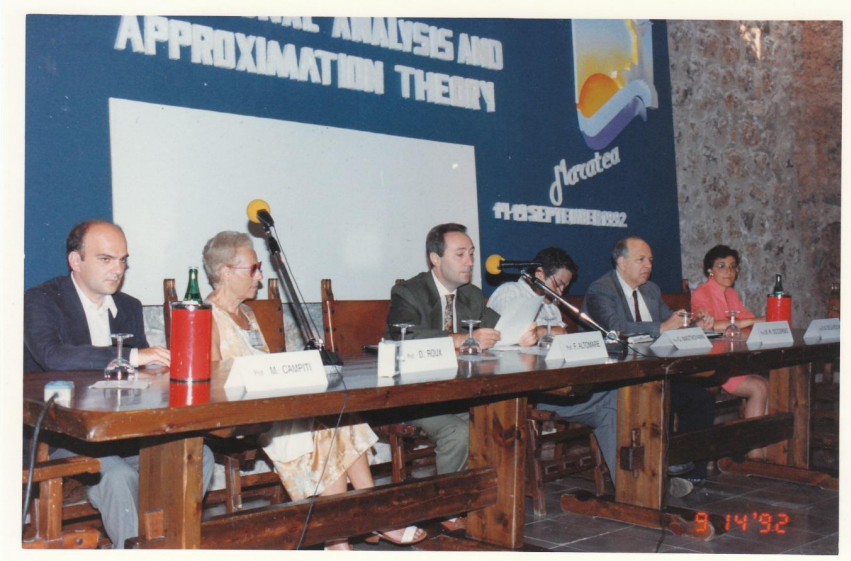

Acquafredda di Maratea, September 1992 - Opening Ceremony of the 2nd FAAT Maratea Conference. From the left: Michele Campiti, Delfina Roux (1927-2018), Francesco, Giuseppe Mastroianni, Mario Rosario Occorsio, Biancamaria Della Vecchia.

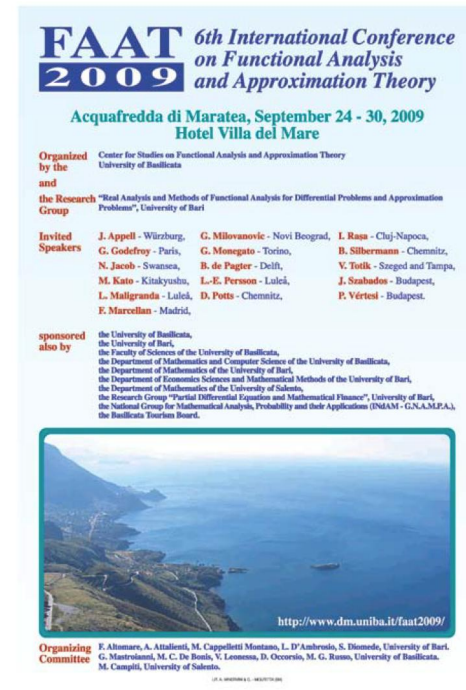

The Conference poster of the last FAAT Conference.

from 1989 to 2018 characterized by several exchanges of visits, 14 joint published papers and a monograph [20] jointly written with the first and second author of this paper. In 2004, they both spent a research period at the Mathematical Institute of Oberwolfach under the Research in Pair program. Professor Raşa has often attended the FAAT Conferences, being also main speaker in some editions.

We now mention a number of additional collaborations Francesco's research group in Bari developed after 1990 that we know he judges as important.

- Professor Romulus Cristescu, University of Bucharest, President of the Section of Mathematical Sciences of the Romanian Academy, and his research group on Riesz spaces and positive operators. Professor Cristescu invited Francesco several times to well-known conferences in Sinaia 
on Riesz spaces and positive operators. In 2003, he also invited Francesco as guest speaker of the 5th Congress of Romanian Mathematicians in Piteşti.

- Professors Elena Moldovan Popoviciu (1924-2009), Dimitrie D. Stancu (1927-2014), and Octavian Agratini from the University Babeş-Bolyai of Cluj-Napoca. Their common scientific interests were concerned with the Approximation Theory by means of positive operators and were developed during several exchanges of visits. Professor Agratini has been one of the main organizers of a series of excellent conferences on Numerical Analysis and Approximation Theory, held in Cluj-Napoca in 2006, 2010, 2014, and 2018, to which Francesco was always invited as main speaker.

- Professors Ioan Gavrea and Mircea Ivan from the Technical University of Cluj-Napoca. They had shared scientific interests in the Approximation Theory by means of positive operators, and soon their interactions extended to their families who are now bound by a warm friendship. Professor Mircea Ivan has been one of the main organizers of the series of Theodor Angheluţă Seminar Conferences which were attended by Francesco several times.

- Professors Pietro Aiena and Camillo Trapani from the University of Palermo and their research group on Operator Theory. Among other things, they developed the national research project "Operator theory, Semigroups and Applications to Evolution Equations and Approximation Problems", sponsored by the Italian Ministry for Education for the years 2003-04 and 2004-05 (PRIN-COFIN 2003).

- Professors Gianluca Vinti and Carlo Bardaro from the University of Perugia, and their research group on Approximation Theory - Laura Angeloni, Danilo Costarelli, Ilaria Mantellini, and Luca Zampogni. Together with their research groups Francesco and Gianluca Vinti developed several national research projects on Methods of Operator Theory for Approximation Problems and Evolution Equations.

- Professors Francisco Javier Muñoz-Delgado and Daniel Cárdenas-Morales from the University of Jaén. They have organized ten editions (2010-2019) of the Jaén Conferences in Approximation Theory which took place in the beautiful city of Úbeda, a world heritage site. These conferences and other exchanges of visits consolidated the scientific collaboration in Approximation Theory with Francesco and his research group.

- Professor Mikio Kato from Kyushu Institute of Technology, who reignited Francesco's interest in Banach Spaces Theory. Professor Kato visited Italy two times to attend the 6th FAAT Conference in 2009 and the Recent Developments in Functional Analysis and Approximation Theory conference in 2011 in Lecce on the occasion of Francesco's 60th birthday. Francesco visited Japan once in September 2006 to attend the Second International Symposium on Banach and Function Spaces 2006, organized by Professor Kato in Kitakyushu. After the conference in Kitakyushu, he was also a guest speaker at the Autumn Congress of Mathematical Society of Japan, held in Osaka in the same month.

Other mathematicians with whom in the late 90s Francesco developed fruitful scientific collaborations have been Professor Elisabetta Mangino from the University of Salento and Professors Antonio Attalienti and Silvia Romanelli from the University of Bari.

Very recently, Francesco started new scientific contacts with some Turkish mathematicians and, in particular, with Professor Tuncer Acar from the Selcuk University of Konya especially in connection with the development of the new journal Constructive Mathematical Analysis founded by him.

The third author of this paper is, like Francesco, Editor of the same journal. Lars-Erik and Francesco met for the first time at the above mentioned conference in Japan in 2006, where both were main speakers. After that they have collaborated and been in contact in several ways both 
professionally and on a more private level. In particular, Lars-Erik was a main speaker at the above mentioned FAAT conference in 2009.

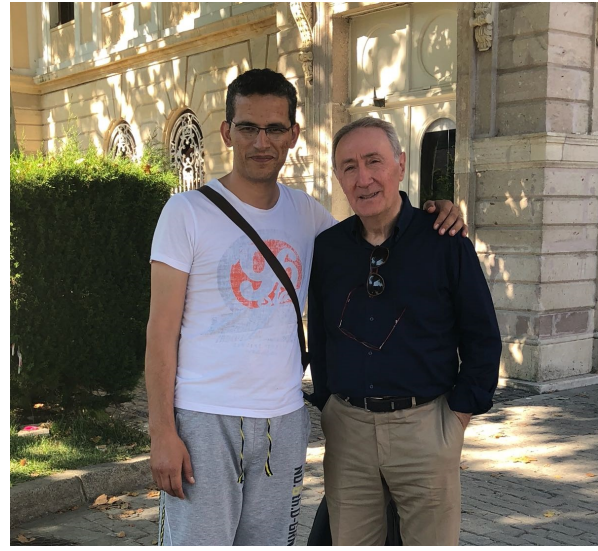

(A)

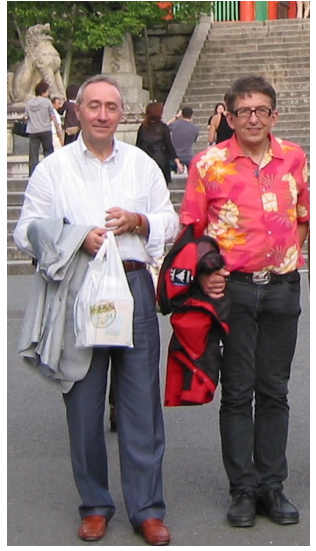

(B)

(A) Istanbul, July 2018, Francesco and Tuncer Acar during the International Conference on Mathematics "An Istanbul Meeting for World Mathematicians", Minisymposium on Approximation Theory \& Minisymposium on Math Education.

(B) Kitakyushu, September 2006, Francesco and Lars-Erik during the International Conference "Second International Symposium on Banach and Function Spaces".

\section{OTHER SELECTED INFORMATION FROM FRANCESCO ALTOMARE'S C.V.}

During his career, Francesco has been appointed on several official posts. In particular, after being, as already mentioned, Director of the Institute of Mathematics at the University of Basilicata from 1987 to 1990, he has served as

- Director of the Graduate School in Mathematics at the University of Bari from 1993 to 1995.

- Head of the Interuniversity Department of Mathematics of the University and the Polytechnic of Bari from 1997 to 1999.

- Coordinator of the Ph.D. School in Mathematics of the University of Bari from 1999 to 2003.

- Head of the Department of Mathematics of the University of Bari from 2012 to 2015.

- Member of the Academic Senate of the University of Bari from 2012 to 2018.

- Member of the Scientific Committee of Italian Mathematical Union from 2012 to 2015.

During the whole year 2011, Francesco was involved in the groundworks of the Committee for the formulation of the new Statute of the University of Bari. Moreover, in 2014, he was one of the main co-founders of the School of Sciences and Technologies of the University of Bari.

Francesco is member of the Italian Mathematical Union as well as of the European Mathematical Society.

Francesco has carried out various academic and scientific assignments at several Italian universities as well as at the Italian Mathematical Union. In particular, in 2007, he was charged by the Italian Mathematical Union to chair the Organizing Committee of the XVIII Congress of that Society which was held in Bari during the period September 24-29, 2007.

Francesco was invited to deliver lectures and postgraduate short courses as well as developed joint researches at several Italian and foreign universities (Napoli, Lecce, Cosenza, Potenza, Roma, Milano, Bologna, Trieste, Salerno, Palermo, Perugia, Sofia, Annaba, Erlangen, 
Konya, Passau, Valencia, Praga, Paseky, Siegen, Vienna, Baku). He has also participated in about sixty international meetings as invited speaker (Italy, Germany, U.S.A., Brasil, Romania, Spain, Hungary, Czech Republic, Russia, Taiwan, Austria, Japan, Tunisia, Turkey, Azerbaijan).

Francesco contributes to Mathematical Reviews as a reviewer and acts as a referee for several national and international journals.

Francesco is or has been also a member of the Editorial Board of the following journals: Conferenze del Seminario di Matematica dell'Università di Bari (Italy, 1990-2003), Revue d'Analyse Numérique et de Théorie de 1'Approximation (Romania, since 1998), Mathematical Reports (Romania, 2000-2012), Journal of Applied Functional Analysis (U.S.A., 2004-2015), Journal of Interdisciplinary Mathematics (India, 2004-2018), Numerical Functional Analysis and Optimization (U.S.A., since 2008), Bollettino dell'Unione Matematica Italiana (Italy, 2008-2012), Studia Mathematica Universitatis Babeş-Bolyai (Romania, since 2009), Demonstratio Mathematica (Poland, since 2017), Constructive Mathematical Analysis (Turkey, since 2018).

Moreover, since 2004 Francesco is the founding Editor-in-Chief of the international journal Mediterranean Journal of Mathematics. It is worth noticing that one of the founding principles and motivations of the journal is to contribute to further integration and collaboration amongst the Mediterranean universities. This aim is reflected in the choice of the title "Mediterranean Journal of Mathematics" and in the composition of the Editorial Board, which includes mathematicians from Mediterranean countries only. Nowadays, the journal has reached an excellent reputation worldwide and publishes about 200 articles per year.

Francesco contributed to the organization of several international meetings and was coeditor of the corresponding proceedings. Among them, we recall the already mentioned six editions of the international conference on Functional Analysis and Approximation Theory held in 1989, 1992, 1996, 2000, 2004, and 2009 held in Acquafredda di Maratea (see Section 4).

Francesco has always been passionate about teaching and, during his career, he has taught several undergraduate, graduate and Ph.D courses. He has also developed an interest in communicating Mathematics to the younger generations, pointing out its deep relationship, not only with the other hard sciences, but also with Art, Music, and Literature. For this reason, following a similar project of other Italian universities, he has supported a close collaboration between the Department of Mathematics of the University of Bari and several High Schools in Puglia and has been appointed director of the Professional Training Course Liceo ad Indirizzo Matematico, devoted to those high-school teachers who want to approach Mathematics in a more inclusive and comprehensive way.

\section{SOME IMPORTANT SCIENTIFIC CONTRIBUtions OF FRAnCESCO AltOMARE}

During his long and fruitful career, Francesco has written more than 90 papers and three monographs (see $[9,14,20]$ ). An overview of Francesco's scientific activity up to 2011 was presented by Michele Campiti in a talk at the conference Recent developments in Functional Analysis and Approximation Theory held in Lecce in 2011 in honor of Francesco's 60th birthday (see [28]). In this section, we focus on some aspects of his scientific career, knowing well enough it is not possible to summarize in a few words the great impact he has had on the mathematical and sciences community.

Francesco's main areas of research as well as his scientific interests may be grouped under the following items:

Real and Functional Analysis (Choquet Integral Representation Theory, Choquet boundaries, continuous function spaces, function algebras and Banach algebras, locally convex vector lattices, positive linear forms and applications to abstract Potential Theory and Harmonic Analysis); 
Operator Theory, Probability Theory and Evolution equations (Positive operators, semigroups of operators, positive semigroups and Markov processes, differential operators and applications to evolution equations);

Approximation Theory (Korovkin-type Approximation Theory, positive approximation processes, approximation of semigroups by means of positive operators, asymptotic formulae, iterates of positive linear operators).

One of the characteristics of Francesco's work is that in most of his papers it is not possible to describe the results obtained in one of the above areas without at least one of the others being involved. Francesco's main scientific achievement is in our opinion to have realized how closely connected those areas are.

This fact is especially evident in the two monographs [14] and [20], where several techniques coming from Real and Functional Analysis, Approximation Theory and Operator Theory, Probability and Evolution Equation Theory are combined clearly showing an overview that he has probably always had in his mind.

In fact, some aspects of the research work of Francesco and his collaborators find their roots in the first results he obtained on $H$-Lion operators (see $[1,2,3]$ ). Such results are the first contributions of Francesco to the Choquet Integral Representation Theory and to the abstract Dirichlet problem. These investigations have as a consequence, for example, the characterization of a Bauer simplex $K$ of a locally convex space in terms of the existence of a unique continuous positive projection on $C(K)$ such that $T(C(K))=A(K)$, where $A(K)$ is the space of all affine functions on $K$, as well as in terms of the existence of a resolvent family $\left(R_{\lambda}\right)_{\lambda>0}$ on $K$ having $A(K)$ as common range and such that $\left(\lambda R_{\lambda}\right)_{\lambda>0}$ is strongly convergent as $\lambda \rightarrow+\infty$.

Other contributions to Choquet's Theory can be found in the papers $[15,16,17]$, whose authors have considered a particular class of positive projections defined on an adapted subalgebra of continuous real-valued functions that can be characterized by means of representing measures concentrated on the Choquet boundary. We also mention the introduction of new classes of locally convex vector lattices of continuous functions on a locally compact Hausdorff space in whose context some Korovkin-type theorems for continuous positive linear operators with respect to the identity operator, to positive projections, and to finitely defined operators were obtained. Besides, in the above mentioned setting an integral representation theorem for positive linear functionals is presented as well.

Approximation Theory has always been one of Francesco's most beloved topics. He has obtained Korovkin-type theorems not only in continuous function spaces, but also in different contexts, such as abstract Riesz spaces (see, e.g., [4]), $L^{p}$ spaces, and weighted continuous function spaces or Banach algebras (see, e.g., [5, 6]). Moreover, he has introduced and studied several classes of approximation processes in spaces of continuous and integrable functions.

Moreover, Francesco has deeply studied asymptotic formulae for positive linear operators and their applications, among other things, to the Central Limit Theorem of Probability Theory, to converse theorems of smoothness and saturation theorems $([8,13,22])$. Besides, much attention has been paid to the study of iterates of positive linear operators and their applications in Ergodic Theory and the constructive approximation of semigroups of operators. For a recent survey on these topics, see [10].

The monograph [14], written by Francesco and Michele Campiti, can be considered as the biggest contribution of these authors to Approximation Theory, since it is highly appreciated by the researchers in that field, which can be judged, for example, by the number of its citations. The monograph presents, for the first time, a comprehensive exposition of the main aspects of the Korovkin-type Approximation Theory. By following an original and systematic approach, the book condenses the main results of the theory obtained during the period 1953-1994, which 
are documented in more than 700 references. Among other things, the reader can find results concerning Korovkin-type theorems for bounded positive Radon measures, for positive linear operators, and for the identity operator (the classical case), realizing the strong connection between this theory and other areas of functional analysis.

Among Francesco's main achievements pertaining the Korovkin-type Approximation Theory we mention the following:

- A Korovkin-type theorem with respect to limit operators which are positive projections (see [14]).

- An extension of the classical Korovkin theorem in the framework of function spaces on metric spaces (see [9]).

- The equivalence between both the algebraic and trigonometric versions of the Korovkin theorems and the algebraic and trigonometric versions of the Weierstrass theorems (see $[9,14])$.

- A characterization of the subalgebras of continuous functions vanishing at infinity on a locally compact Hausdorff space in terms of Korovkin closures. This, in particular, leads to an equivalence between the Bauer extension of the Korovkin theorem in the above mentioned more general setting and the Stone extension of the Weierstrass theorem in the same setting. Such equivalence enlights the deep and beautiful relationship between these milestones of the Approximation Theory which reflects two different points of view: a constructive and a qualitative one, respectively (see $[9,14])$.

In [14], there are also several applications to the approximation of continuous functions by positive linear operators, together with applications to the approximation and the representation of the solutions of particular partial differential equations of diffusion type by means of iterates of suitable positive linear operators. The connection between Approximation Theory and Evolution Equations lies in those results.

Subsequently, all aspects treated in [14] were taken up by Francesco.

The monograph [14] already contains the germ of a new theory which would have been developed during the subsequent twenty years by Francesco and his collaborators and which found a rather complete synthesis in the monograph [20], jointly written with the first and second authors of this paper and Ioan Raşa. The main aim of this theory is the study of a large class of (mainly degenerate) initial-boundary evolution problems in connection with the possibility to investigate whether they can be described by positive semigroups and, in such a case, whether it is possible to approximate such semigroups by means of iterates of suitable positive linear operators which also constitute approximation processes in the underlying Banach function space.

By using such kind of approximation, after a careful analysis of the preservation properties of the approximating operators, such as monotonicity, convexity, Hölder continuity and so on, the hope is to infer similar preservation properties for the relevant semigroup and, consequently, some spatial regularity properties of the solutions to the evolution problems as well as their asymptotic behaviour, i.e., their long-term behavior as the "temporal" parameter $t$ tends to infinity.

In what follows, we briefly describe some important differential problems which can be treated by using the ideas developed by Francesco scientific career.

Fix a convex compact subset $K$ of $\mathbb{R}^{d}(d \geq 1)$ with non-empty interior and a positive linear operator on $T: C(K) \rightarrow C(K)$ such that $T(\mathbf{1})=\mathbf{1}, \mathbf{1}$ being the constant function of value 1 . Then, consider the elliptic second-order differential operator $W_{T}$ defined as

$$
W_{T}(u):=\frac{1}{2} \sum_{i, j=1}^{d} \alpha_{i j} \frac{\partial^{2} u}{\partial x_{i} \partial x_{j}} \quad\left(u \in C^{2}(K)\right),
$$


where, for each $i, j=1, \ldots, d$ and $x \in K, \alpha_{i j}(x):=T\left(p r_{i} p r_{j}\right)(x)-\left(p r_{i} p r_{j}\right)(x), p r_{i}$ being the $i$-th coordinate function (i.e. $p r_{i}(x)=x_{i}$ for every $x \in K$ ).

Operators of the form $W_{T}$ are of great importance in the study of several diffusion problems arising in population genetics, financial mathematics and other fields.

Because of the degeneracy of $W_{T}$ on the set $\partial_{T} K:=\{x \in K \mid T(f)(x)=f(x)$ for every $f \in$ $C(K)\}$ of all interpolation points for $T$ and the fact that the boundary $\partial K$ of $K$ is generally non-smooth, the methods of the theory of partial differential equations might fail in studying such problems. However, there are no such difficulties in the theory developed by Francesco and his co-authors.

Consider the initial boundary value problem associated with $\left(W_{T}, C^{2}(K)\right)$ and the initial value $u_{0}$ belonging to a suitable subset of $C^{2}(K)$ :

$$
\begin{cases}\frac{\partial u}{\partial t}(x, t)=\frac{1}{2} \sum_{i, j=1}^{d} \alpha_{i j}(x) \frac{\partial^{2} u}{\partial x_{i} \partial x_{j}}(x, t) & x \in K, \quad t \geq 0 ; \\ u(x, 0)=u_{0}(x) & x \in K .\end{cases}
$$

One of the first problems deals with showing whether the operator $W_{T}$ defined on $C^{2}(K)$ is the (pre)-generator of a strongly continuous semigroup $(T(t))_{t \geq 0}$ on $C(K)$; if this is the case, it is well known that, for any $u_{0}$, such a problem has a unique solution given by $u(x, t)=$ $T(t)\left(u_{0}\right)(x)(x \in K, t \geq 0)$, and the solution continuously depends on the initial value $u_{0}$.

Therefore, we have at our disposal the solution of the above differential problem in terms of the semigroup (pre)-generated by the elliptic operators underlying it. Unfortunately, usually we do not know an explicit expression for the semigroup, and as a consequence of the solution.

The second aim is to construct a suitable positive approximation process $\left(L_{n}\right)_{n \geq 1}$ on $C(K)$, such that, for every $t \geq 0$ and $f \in C(K)$,

$$
T(t) f=\lim _{n \rightarrow \infty} L_{n}^{k_{n}} f \quad \text { uniformly on } K
$$

for a suitable sequence $\left(k_{n}\right)_{n \geq 1}$ of positive integers (independent on $f$ ), where each $L_{n}^{k_{n}}$ denotes the iterate of $L_{n}$ of order $k_{n}$.

Then, combining the above results, we get an approximation formula for the solutions to (6.1), i.e.,

$$
u(x, t)=T(t)\left(u_{0}\right)(x)=\lim _{n \rightarrow \infty} L_{n}^{k_{n}}\left(u_{0}\right)(x),
$$

from which we can try do derive both numerical and qualitative information about $u$ from the study of the operators $L_{n}$.

The positive linear operators that are used to prove both the generation and the approximation properties of the semigroup $(T(t))_{\geq 0}$ are the so-called Bernstein-Schnabl operators $B_{n}$ associated with $T$ and are defined, for every $n \geq 1, f \in C(K), x \in K$, by

$$
B_{n}(f)(x):=\int_{K} \cdots \int_{K} f\left(\frac{x_{1}+\ldots+x_{n}}{n}\right) d \tilde{\mu}_{x}^{T}\left(x_{1}\right) \cdots d \tilde{\mu}_{x}^{T}\left(x_{n}\right),
$$

where, for every $x \in K, \tilde{\mu}_{x}^{T}$ is the unique probability Borel measure on $K$ associated with $T$ via the Riesz representation theorem.

Bernstein-Schnabl operators, first introduced by Schnabl (see [30]) and successively by other authors in different contexts, were intensively studied by Francesco since the late '80s (see [7], [14, Section 6.1] and the references therein). In the above mentioned works, though, it was assumed that the underlying operator $T$ is a positive projection satisfying suitable assumptions. Francesco overcame such a limitation first in the context of the interval $[0,1]$, in the joint work 
[23] with the second author of this paper and Ioan Raşa, and then in the context of compact convex sets of $\mathbb{R}^{d}$ (see $[18,20]$ ).

Note that similar results hold in the case where $K$ is a convex compact subset of a (not necessarily finite dimensional) locally convex Hausdorff space $X$. Furthermore, BernsteinSchnabl operators associated with $T$ are useful not only to constructively approximate suitable Markov semigroups, but they are also an approximation process for continuous functions on $K$.

Subsequently, Francesco and his collaborators have also tackled similar problems in different function spaces (for instance $L^{p}$-spaces) and for differential operators of the complete form $V_{T}(u):=W_{T}(u)+\sum_{i=1}^{d} \beta_{i} \frac{\partial u}{\partial x_{i}}+\gamma u\left(u \in C^{2}(K)\right)$, where $\beta_{1}, \ldots, \beta_{d}, \gamma \in C(K)$ satisfy suitable assumptions (see, e.g., [21]).

Other than the construction of suitable approximation processes which would approximate the semigroups, the key properties which guarantee the solution of the above mentioned problems are asymptotic formulae for the involved approximation operators and the assumption that the operator $T$ maps polynomials on $K$ into polynomials of the same degree. This last aspect has led to investigate the delicate problem of the existence of such operators. In [19] (see also [20, Section 4.3]), among other things it is shown that if $K$ is strictly convex, then such operators exist if and only if $K$ is an ellipsoid. In this case, a classification of such operators is given in terms of the Poisson operators associated with suitable strictly elliptic differential operators. Besides, in the two-dimensional case, a complete characterization of those compact subsets $K$ which admit a non-trivial Markov projection on $C(K)$ preserving polynomials of the same degree has been obtained in [27, Section 4] (see also [20, Appendix A.1]). There a complete description of the relevant Markov projections is also given.

In developing the above mentioned theory some new aspects have been disclosed pertaining the classical Approximation Theory. These new aspects have enlightened new perspectives in the study of the positive approximation processes both in the one dimensional and multidimensional settings. It has been shown, indeed, that almost all the most important positive approximation processes studied in Approximation Theory generate positive semigroups whose generators can be explicitly determined.

Accordingly, it turns out that these classical approximation processes are extremely useful, not only to constructively approximate continuous or integrable functions, but also to approximate and to study qualitative properties of the solutions of several classes of initial-boundary value evolution problems which are of interest in applied sciences.

The investigations related to these problems delineated, in fact, a new research field whose contributions have been given by several mathematicians, mainly from Italy, Romania and Germany. For some references to this respect, we refer to [24].

As regards the determination of suitable approximation processes which would approximate the semigroups, we mention that, other than Bernstein-Schnabl operators, several other classes have been constructed, all depending on a given positive linear operator. Among them we cite Lototsky-Schnabl operators (see [14, 20]) and generalized Kantorovich operators (see [21]). The problem of constructing new approximation processes related to a positive linear operator seems to have an independent interest and constitutes a further promising research field.

Moreover Francesco, together with some collaborators, studied semigroups of positive operators also in connection with elliptic boundary value problems and Markov processes, especially in the setting of weighted continuous function spaces. We refer, e.g., to [25] and [26] and the references therein, for more details in this respect. 
We end the section by pointing out that very recently Francesco has undertaken the study of convergence criterions for positive linear operators and functionals acting on spaces of bounded functions which are continuous only on suitable subsets of their domains. The first results in this direction are contained in [11].

\section{FranCesco Altomare AS SUPERVisOR}

Francesco supervised the scientific activities of several undergraduate and postgraduate research fellows as well as Ph.D students. Many of them have later been appointed as professors.

\section{Ph.D students}

- Sabrina Diomede, Ph.D School at the University of Naples Federico II, 1998-2002. Ph.D thesis: Positive approximation processes on continuous function spaces.

- Mirella Cappelletti Montano, Ph.D School at the University of Bari, 2000-2003. Ph.D thesis: Approximation problems by positive operators in adapted spaces.

Rachida Amiar, Ph.D School at the University of Annaba (Algeria), 1998-2005. Ph.D thesis: Méthode des opérateurs positifs pour l'étude des equations de diffusion.

- Vita Leonessa, Ph.D School at the University of Bari, 2002-2005. Ph.D thesis: Positive linear operators associated with continuous selections of Borel measures.

- Sabina Milella, Ph.D School at the University of Bari, 2002-2005. Ph.D thesis: Evolution equations on real intervals, semigroups and their approximations.

- Graziana Musceo, Ph.D School at the University of Bari, 2003-2006. Ph.D thesis: Positive semigroups and evolution equations in weighted continuous function spaces.

\section{Research fellows}

- Daniela Sforza, Junior C.N.R. research fellowship (1982-1983).

- Cinzia Lucia Zifarelli, Senior C.N.R. research fellowship (1987-1988).

- Michele Campiti, I.N.d.A.M. research fellowship (1988-1990).

- Elvira Romita, Junior C.N.R. research fellowship (1994-1995).

- Ingrid Carbone, Senior C.N.R. research fellowship (1995-1996).

- Marco Romito, Senior C.N.R. research fellowship (1995-1996).

- Sabrina Diomede, Junior C.N.R. research fellowship (1996-1997).

- Lorenzo D'Ambrosio, Junior C.N.R. research fellowship (1997-1998).

- Mirella Cappelletti Montano, Research Fellowship University of Bari (2005).

- Vita Leonessa, I.P.E. Post-doc fellowship (2006).

- Sabina Milella, Post-doc fellowship University of Bari (2007-2009).

- Graziana Musceo, Post-doc fellowship University of Bari (2009-2011).

Francesco paid a lot of care and attention to his students, not only from a merely scientific point of view, but also from an academic and human one. With most of them he has written joint papers.

Francesco promoted the birth of a Ph.D program in Mathematics at the University of Bari in 1999 and he was its first Coordinator. As a matter of fact, many of his Ph.D students were enrolled in that program. He put many efforts in building a Ph.D School in Bari because he strongly believes in sharing knowledge and experience with students and in creating an environment where they can learn what being a good mathematician means.

Francesco is a very generous supervisor and collaborator. The door of his office is always open and he is very happy to talk with his students and co-authors about (but not only) Mathematics. 


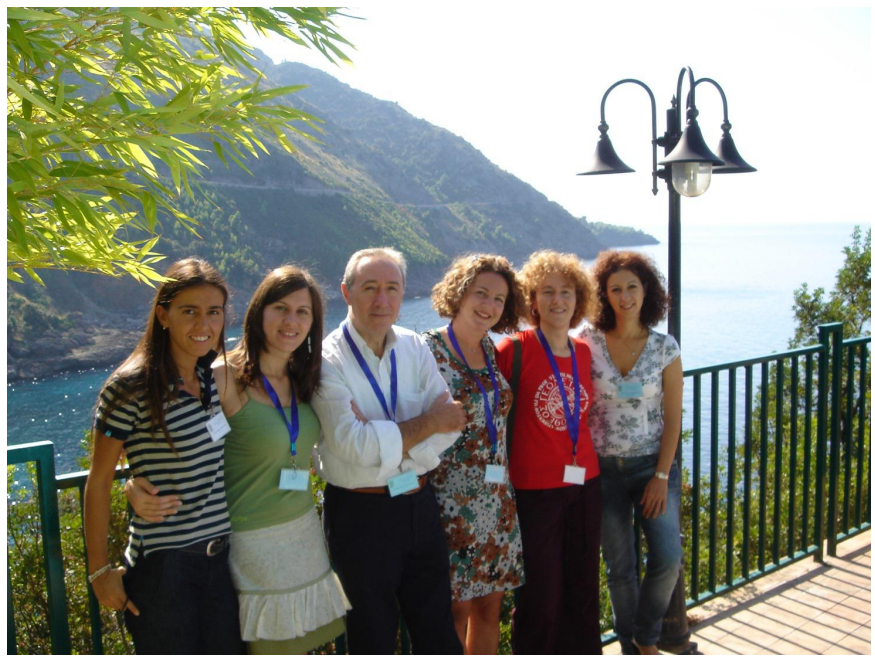

Acquafredda di Maratea, 6th FAAT Conference, September 2009 - Francesco and some of his Ph.D students. From the left: Graziana Musceo, Vita Leonessa, Francesco, Sabrina Diomede, Sabina Milella, Mirella Cappelletti Montano.

He thinks that the devil lies in the details, so he approaches every Mathematical problem with rigor and care. He has thought this valuable lesson to all his students as well.

Mirella and Vita, the two first authors of this article, think that they have been lucky enough to be Ph.D students of Francesco and they are still in the lucky situation of continuing to collaborate with him. They are deeply grateful to him for his continuous encouragement over the years and they feel honored for his friendership.

\section{Final Words about Francesco Altomare}

As seen in our descriptions above the great contributions of Professor Francesco Altomare to mathematical research and Ph.D education, and his unique status in the mathematical community is obvious and worldwide well known. We will finalize our writing by also giving some final words about this remarkable mathematician and human being.

* Francesco is married and he has two children and one grandchild. The family is very important to him.

* Francesco has chosen to live his whole life in his small hometown Giovanazzo, 18 kilometers away from the regional capital Bari.

* Francesco is a really warmhearted and open-minded person, which it is very easy to like and collaborate with.

* Throughout his life Francesco has kept interests concerning subjects other than Mathematics, e.g., Greek and Latin Classics, art (especially on the Renaissance and the Impressionism), poetry and Italian literature.

* During his youth Francesco contributed to the family purse by doing small jobs, including giving amateur guitar lessons. Moreover, he played in a beat band.

* Francesco was also early interested in sports. In particular, he participated in local championships in basketball and coordinated a sports association for young people in his hometown.

* Francesco was invited to partake in the local city politics, and in fact he was city councilor for three years. 
* Francesco continues to give contributions to the cultural activities in Giovinazzo. For example, he was the co-founder of a cultural association which, among other things, makes a library for children available to citizens. Moreover, he periodically gives some lectures on the beauty of Mathematics which are intended to a broad audience.

* Francesco was educated with a strong sense of religion. He often participated in religious functions and he has even performed musical pieces on the church organ.

We want to end this paper by thanking Francesco for having inspired many of us in various ways both as an excellent mathematician and as a warmhearted and especially great human being.

Thank you Francesco for everything, in particular,

* for all wonderful new knowledge and innovative ideas you have given to the mathematical sciences;

* for providing us collaborators, including all Ph.D students, with your positive and supportive spirit and ideas to mathematics and life;

* for always being open for and looking forward new adventures in the future;

* for being our dear friend and still a very active main collaborator and ideal for us.

\section{Dear Francesco,}

we hereby give you our warmest and most cordial congratulations on your +25 birthday and hope for many years more in collaboration and life with you as our inspirer and friend.

\section{ACKNOWLEDGMENTS}

Work performed by the first and the second author under the auspices of G.N.A.M.P.A. (INdAM).

\section{PERMISSION}

The pictures present in the paper belong to Prof. Francesco Altomare and we have permission to use them.

\section{REFERENCES}

[1] F. Altomare: Proiettori positivi, famiglie risolventi e problema di Dirichlet, Ricerche Mat., 26 (1) (1977), 63-78.

[2] F. Altomare: Operatori di Lion generalizzati e famiglie risolventi, Boll. Un. Mat. Ital. B (5), 15 (1) (1978), 60-79.

[3] F. Altomare: Lion operators over the product of compact spaces, semigroups of positive operators, and the Dirichlet problem, Ricerche Mat., 27 (1) (1978), 33-58.

[4] F. Altomare: Théorèmes de convergence de type Korovkin relativement a une applications lineaire positive, Boll. Un. Mat. Ital. B (5), 16 (3) (1979), 1013-1031.

[5] F. Altomare: On the universal convergence sets, Ann. Mat. Pura Appl., 138 (4) (1984), 223-243.

[6] F. Altomare: Positive linear forms and their determining subspaces, Ann. Math. Pura Appl., 154 (4) (1989), 243-258.

[7] F. Altomare: Limit semigroups of Bernstein-Schnabl operators associated with positive projections, Ann. Scuola Norm. Sup. Pisa Cl. Sci. (4), 16 (2) (1989), 259-279.

[8] F. Altomare: Asymptotic formulae for Bernstein-Schnabl operators and smoothness, Bollettino U.M.I., II (9) (2009), 135150, Corrigendum: Bollettino U.M.I., IV (9) (2011), 259-262.

[9] F. Altomare: Korovkin-type theorems and approximation by positive linear operators, Surv. Approx. Theory, 5 (2010), 92-164.

[10] F. Altomare: Iterates of Markov operators and constructive approximation of semigroups, Constr. Math. Anal., 2 (1) (2019), 22-39.

[11] F. Altomare: On the convergence of sequences of positive linear operators and functionals on bounded function spaces, Proc. Amer. Math. Soc., to appear. DOI: https://doi.org/10.1090/proc/15445. 
[12] F. Altomare et al: The Maratea Conferences on Functional Analysis and Approximation Theory from 1989 to 2009-An overview, 2009, free available on line at https://galileo.dm.uniba.it/Members/altomare/ Maratea-Conferences.pdf.

[13] F. Altomare, R. Amiar: Asymptotic formulae for positive linear operators, Mathematica Balkanica New Series, 16 (2002), Fasc. 1-4, 283-304.

[14] F. Altomare, M. Campiti: Korovkin-type approximation theory and its applications, De Gruyter Studies in Mathematics, 17, Walter de Gruyter \& C., Berlin (1994).

[15] F. Altomare, M. Cappelletti Montano: Affine projections on adapted subalgebras of continuous functions, Positivity, 9 (4) (2005), 625-643.

[16] F. Altomare, M. Cappelletti Montano: Regular vector lattices of continuous functions and Korovkin-type theorems - Part I, Studia Math., 171 (3) (2005), 239-260.

[17] F. Altomare, M. Cappelletti Montano: On some density theorems in regular vector lattices of continuous functions, Collect. Math., 58 (2) (2007), 131-149.

[18] F. Altomare, M. Cappelletti Montano, V. Leonessa and I. Raşa: On differential operators associated with Markov operators, J. Funct. Anal., 266 (6) (2014), 3612-3631.

[19] F. Altomare, M. Cappelletti Montano, V. Leonessa and I. Raşa: On Markov operators preserving polynomials. J. Math. Anal. Appl., 415 (1) (2014), 477-495.

[20] F. Altomare, M. Cappelletti Montano, V. Leonessa and I. Raşa: Markov operators, positive semigroups and approximation processes, De Gruyter Studies in Mathematics 61, De Gruyter, Berlin (2014).

[21] F. Altomare, M. Cappelletti Montano, V. Leonessa and I. Raşa: Elliptic differential operators and positive semigroups associated with generalized Kantorovich operators, J. Math. Anal. Appl., 458 (1) (2018), 153-173.

[22] F. Altomare, S. Diomede: Asymptotic formulae for positive linear operators: direct and converse results, Jaén J. Approx., 2 (2) (2010), 255-287.

[23] F. Altomare, V. Leonessa and I. Raşa: On Bernstein-Schnabl operators on the unit interval, Z. Anal. Anw., 27 (3) (2008), 353-379.

[24] F. Altomare, V. Leonessa: An invitation to the study of evolution equations by means of positive linear operators, Lecture Notes of Seminario Interdisciplinare di Matematica, 8 (2009), 1-41.

[25] F. Altomare, S. Milella and G. Musceo: On a class of positive C0-semigroups on weighted continuous function spaces, Note Mat., 31 (1) (2011), 15-27.

[26] F. Altomare, S. Milella and G. Musceo: Multiplicative perturbations of the Laplacian and related approximation problems, J. Evol. Equ., 11 (2011), 771-792.

[27] F. Altomare, I. Raşa: Towards a characterization of a class of differential operators associated with positive projection, Atti Sem. Mat. Fis. Univ. Modena, 46 (1998), suppl., 3-38.

[28] M. Campiti: On the scientific heritage of Professor Francesco Altomare. A presentation of some meaningful results, Recent developments in Functional Analysis and Approximation Theory, Lecce (Italy) (2011), unpublished.

[29] A. Pietsch: History of Banach spaces and linear operators, Birkhäuser Boston, Inc., Boston, MA (2007).

[30] R. Schnabl: Eine verallgemeinerung der bernsteinpolynome, Math. Ann., 179 (1968), 74-82.

Mirella Cappelletti Montano

UNIVERSITY OF BARI

DEPARTMENT OF MATHEMATICS

VIA E. ORABONA, N. 4, 70125 BARI, ITALY

ORCID: 0000-0003-1850-0428

E-mail address: mirella.cappel lettimontanoduniba.it

\section{VITA LEONESSA}

UNIVERSITY OF BASILICATA

DEPARTMENT OF MATHEMATICS, COMPUTER SCIENCE AND ECONOMICS

Viale Dell' Ateneo LuCANo, NO. 10, 85100 PotenzA, ITAly

ORCID: 0000-0001-9547-8397

E-mail address: vita. leonessa@unibas.it 
LARS-ERIK PERSSON

UiT THE ARCTIC UNIVERSITY OF NORWAY, CAMPUS NARVIK

DEPARTMENT OF COMPUTER SCIENCE AND COMPUTATIONAL ENGINEERING

LODVE LANGES GATE 2, 8514 NARVIK, NORWAY

KARLSTAD UNIVERSITY

DePARTMENT OF MATHEMATICS AND COMPUTER SCIENCE

UNIVERSITETSGATAN 2, SE-65184, KARLSTAD , SWEDEN

ORCID: 0000-0001-9140-6724

E-mail address: larserik6pers@gmail.com 